\title{
MODELLING PASSENGER DISTRIBUTION ON METRO STATION PLATFORM
}

\author{
Nikola Krstanoski ${ }^{1}$ \\ ${ }^{1}$ Faculty for Technical Sciences, Department for Transport and Traffic Engineering, University "St. \\ Kliment Ohridski”, Bitola, Macedonia
}

Received 14 August 2014; accepted 25 October 2014

\begin{abstract}
The problems such as design of a metro station, an analysis of the station or line performance characteristics, simulation of passenger alighting and boarding process, simulation of metro line operation, etc. involve the need to get much better knowledge about the behavior of the passengers on the station platform in terms of their distribution among train doors in relation with the station design elements. Despite this, there have been only very limited number of researchers that tackled this problem. In this article, a model of passenger distribution among metro train doors has been developed. The model has been based on the data collected from the Bloor metro station in Toronto, Canada. Metro trains were video-taped during two-hour study period and data were obtained for the number of alighting and boarding passengers per each door and per each train. The results of the statistical analysis have shown that multinomial probability distribution appears to be a good model to describe passenger boarding and alighting process. It also has been shown that there has been clear dependence of the passenger distribution among train doors on the position of the platform entrance and exit points.
\end{abstract}

Keywords: modeling, metro station, passenger distribution, metro platform.

\section{Definition of the Problem}

Large and often medium size urban conglomerations have been known to create distinct transport corridors with heavy demand for travel. The most efficient and environmentally friendly way to serve those corridors is to use a high-performance transportation mode that consists of highcapacity Transit Units - TU (multiple car consists or trains) operating on a separate right-of-way, at high speed and high frequency of service. These characteristics are features of the Metro (Rapid Transit, Subway) mode.
The efforts to achieve and maintain an operation of metro line at high capacity and level of service lead to the need to consider variety of problems such as design of a metro station, an analysis of the station or line performance characteristics, simulation of passenger alighting and boarding process, simulation of metro line operation, etc. Analysis of these problems may require much better knowledge about the behavior of passengers on the station platform in terms of their distribution among train doors in relation with the station design elements. However, there have been only very limited number of researchers that tackled this problem.

${ }^{1}$ Corresponding author: nikola.krstanoski@tfb.uklo.edu.mk 
Among the rare studies that have addressed this problem is the one done by Szplett and Wirasinghe (1984a; 1984b) who investigated the train standing times and passenger boarding and alighting times at LRT stations in Calgary, Canada. Their research included an extensive analysis of the passenger distribution among train doors as a function of the station platform design. The results of their analysis show that the position of platform exits/ entrances has a significant influence on the passenger distribution. The station with only one exit/entrance at the end of the platform causes a concentration of passengers near the exit/entrance. This passenger distribution is found to follow a negative exponential distribution. A station with several platform entrances resulted in a more even passenger distribution and is modeled by means of a normal distribution.

Another study of station dwell time and passenger's distribution on a station platform was done at the University of Toronto by Mori (1988). The results of the dwell time simulation model developed as a part of the research, suggested that if the passenger distribution among train doors had been uniform, the dwell time would've been about $15 \mathrm{~s}$ shorter.

Rather detailed analysis of the passenger distribution on metro station platform has been given in the research done by Krstanoski (1996) as part of the Ph. D. thesis on metro line performance and level of service. There, a model of passenger distribution among metro train doors has been developed, based on the data collected from the Bloor metro station in Toronto, Canada. These high quality data are used to build a simulation model of passenger behavior on the station platform and later to model the station dwell times and the operation of the entire metro line. The section concerned with the modeling of passenger's distribution among train doors is presented in this article.

More recent study in this area has been done by Wu et al. (2012). In their paper, based on a data collected on a metro station in Bejing, they proposed a potential energy model that would describe the passenger distribution among train doors prior to arrival of train at the station. The data used for building the model, was collected by manual counting and video-taping.

\section{Boarding and Alighting Process: Definitions and Characteristics}

The process of boarding and alighting of passengers at metro station has several important characteristics.

Since metro systems utilize stations with fully controlled access, the passengers coming to a station pay their fare before entering the boarding platforms. Consequently, the payment procedure itself does not influence the boarding and alighting process.

After entering the paid area, transit users position themselves along the platform and wait for the next TU. What position is chosen by each individual depends on various factors. Regular transit users may take into consideration the position of the platform exit at their destination station. Also, from their experience they may have noticed that some cars are usually more crowded than others, so that they position themselves where they expect less crowded car to stop. However, when there is no time to walk along the platform, they will board at the TU door close to the platform entrance. Other users simply stay near the station entrance in order to avoid additional 
walking on the platform. Some people chose their position by taking into account the crowdedness on the platform. They prefer areas where they feel it is more comfortable to stand. Finally, there is a group of users who do not choose any particular position intentionally, or their choice is influenced by other random factors, such as meeting a friend or avoiding other people.

As a result of all of these factors, the passengers' distribution along the station platform usually ends up with passengers scattered along the entire platform length with densities that vary but that are influenced to some extent by the position of the station exits and entrances. Exceptions can be found in some automated metro systems that have markings on the platform at stations that designate the positions of TU doors so that passengers usually form lines at those markings (BART - San Francisco).

The number of passengers per TU and their distribution along the platform determines the number of boarding passengers per each TU door. Another important factor that influences this number is the number of TU doors/channels per TU per side.

The distribution of alighting passengers inside the $\mathrm{TU}$ determines the number of alighting passengers at each door. If the movement of passengers between cars of a TU is neglected (some metro systems do not allow movements between cars and also in case of large passenger volumes and high TU loads that movement is difficult or practically impossible), the distribution of alighting passengers will depend on which car passengers have boarded. This means that the same factors that influence the boarding passengers' distribution will influence the distribution of alighting passengers. However, since passengers that alight at a particular station have boarded at different stations, the resulting distribution of alighting passengers in the TU will depend on the passenger behavior and system design elements at all previous stations. This may lead to an intuitive idea that the unevenness in the number of alighting passengers per door is likely to be a result of random fluctuations of an otherwise uniform distribution, except in the case when most previous stations have a design that causes the same uneven distribution, or the alighting station has only one exit and significant number of passengers have chosen to board a car that is closest to that exit.

The number of alighting passengers per $\mathrm{TU}$ is also a random variable, but it depends on the number of on-board passengers (TU load) and the attractiveness of the station that can be measured through the number of alighting passengers per unit time at that station.

\section{Boarding and Alighting Process Survey}

A thorough analysis of the boarding and alighting process requires a large amount of data that have to be collected simultaneously and over a sufficiently long time interval. These data should include the number of alighting and boarding passengers per $\mathrm{TU}$, their distribution among doors for each TU, number of on-board passengers, boarding and alighting time at each door for each TU, and the headways between TUs arriving at the station. Such data are not collected by transit agencies and especially organized survey had to be conducted.

The survey on the number of passengers and their distribution among train doors was done on a northbound platform of Bloor 
Station on the metro line in Toronto. The primary access point is located at the north end of the platform. One other smaller exit which allows access to the street is found near the south end of the platform. The layout is illustrated in Fig. 1. The Toronto Transit Commission (TTC) operates the Yonge Street Line using rail vehicles with three double doors on each side of these vehicles and they operate in eight car trains.

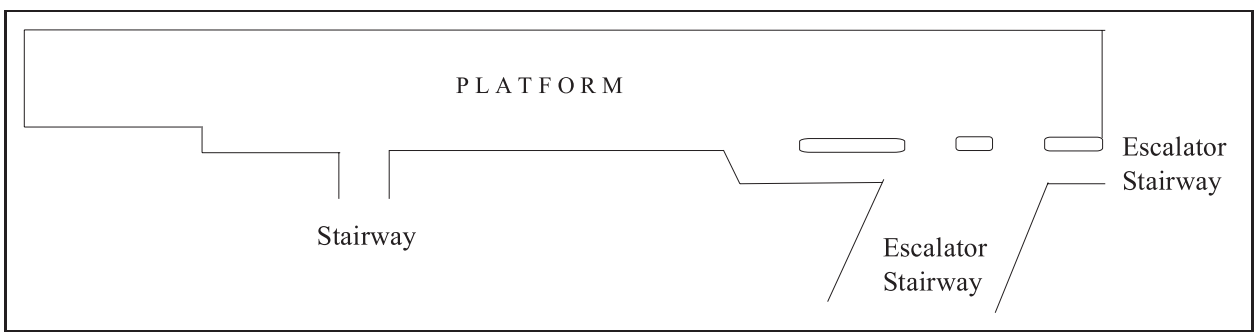

Fig. 1.

Bloor Station Northbound Platform Layout

The data collection was made by means of five video-tape cameras set up along the platform. Later, all data was extracted from the video tapes.

\section{Results of the Analysis of the Survey Data}

The data collected for the number of alighting and boarding passengers per each of the 24 train doors of 44 trains during the survey over a period of two hours allow a closer look at the distribution of passengers among doors. These data have been converted in percentages of total number of passengers per train.

Fig. 2 and Fig. 3 show the data from the two hour survey that has been divided into four periods, each containing 11 trains. The average percent of boarding and alighting passengers per door for each set of 11 trains was computed, as well as the overall average for all 44 trains.

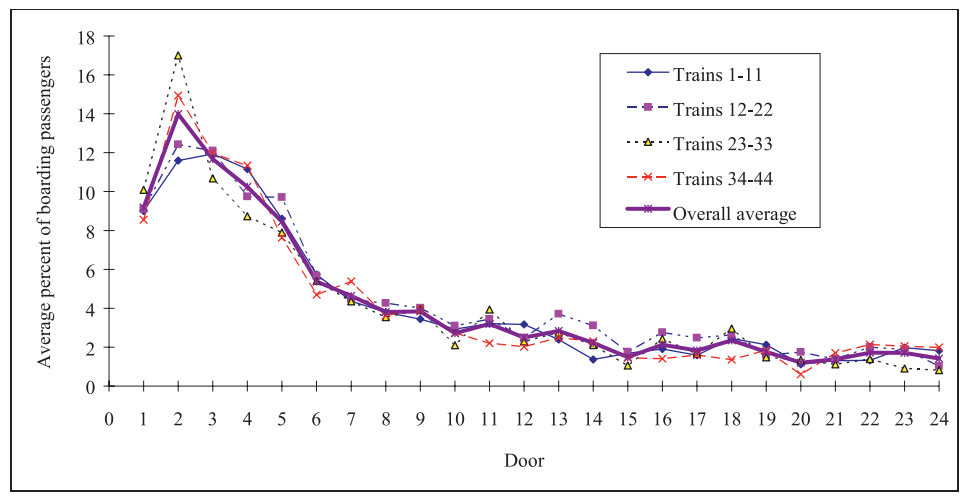

Fig. 2.

Stability of the Boarding Passenger Distribution per Door (Bloor Station, Toronto) 


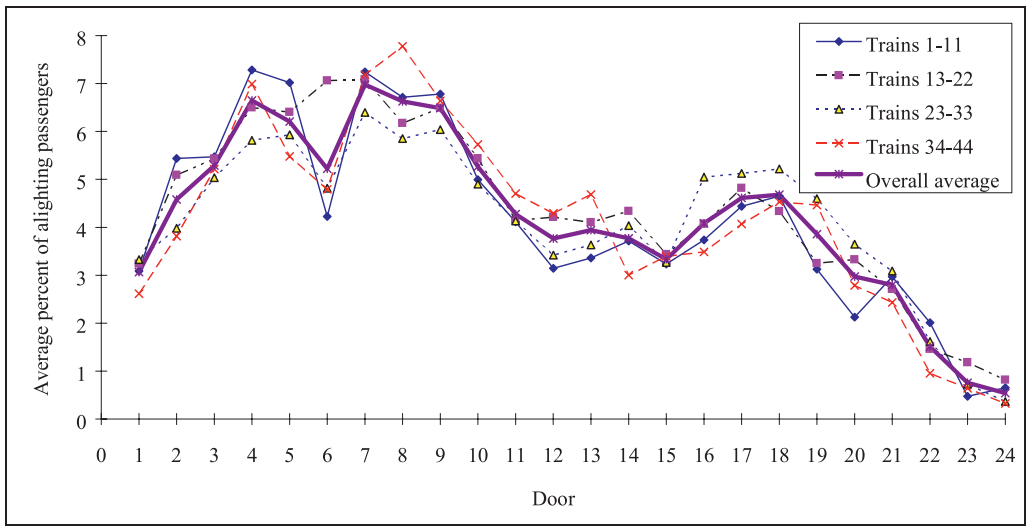

Fig. 3.

Stability of the Alighting Passengers Distribution per Door (Bloor Station, Toronto)

As can be seen from these figures, the boarding passengers were concentrated at the first car of the train, which is the closest to the station's only transfer and entrance point. The distribution of alighting passengers is somewhat more diffused, but still with a higher concentration of passengers at the doors of the first and second train car which are again the closest to the only transfer point. An interesting observation is the smaller peak of alighting passengers near the second smaller exit from the station platform.

The noted distribution of passengers among train doors clearly shows that there is a significant influence of the platform exit/ entrance positions. Also, it is important to notice that these passenger distribution patterns show stability over the time. Similar percentages of alighting and boarding passengers per train doors were recorded for all 44 surveyed trains.

These properties of the passenger distribution among doors are consistent with the results of other similar studies. A strong dependence of the passenger distribution on the position of the station platform exits/entrances and stability of this distribution over the period of survey, was also reported by Szplett and Wirasinghe (1984). Another strikingly similar finding from these two studies, despite the fact that entirely different systems were surveyed (LRT station in Calgary and RT station in Toronto), is the distribution of passengers among doors when there is only one exit/entrance at one end of the station platform. Szplett and Wirasinghe (1984a) found a negative exponential distribution with high passenger concentration at train doors near the exit/entrance, which then exponentially decreased toward the other end of the train (platform). This is the general shape of the boarding passenger distribution at Bloor Station in Toronto.

The property that the percentages (or probabilities) of boarding/alighting per door appears to be stable over the time, brings up the possibility of modeling the process of passenger distribution among doors by means of a probability distribution.

Let us denote the number of boarding passengers per TU with $B$. This is a random variable. For any specific realization $B=$ $b$, out of $b$ passengers that board the TU, 
$b_{1}$ passengers board at door $1, b_{2}$ at door 2 etc., with (constant) probabilities $p_{1}, p_{2} \ldots$ respectively. The number of passengers at door $d-b_{d}$ is random, but the conditions:

$\sum_{d=1}^{n_{d}} b_{d}=b$ and $\sum_{d=1}^{n_{d}} p_{d}=1$

where $n_{\mathrm{d}}$ is the number of doors per TU, are always satisfied.

The conditions given by the Eq. (1) further lead to the idea that a multinomial probability distribution might be a reasonable model for this purpose.

Given that there are $\mathrm{B}=\mathrm{b}$ passengers boarding the TU, the conditional probability that there are $b_{1}$ passengers at door $1, b_{2}$ passengers at door 2 etc., when probabilities to board at each door are $p_{1}, p_{2}$, etc., respectively, has a distribution function:

$\mathrm{P}\left(b_{1}, b_{2}, \ldots, b_{n_{d}} / B=b\right)=\frac{b !}{b_{1} ! b_{2} ! \ldots b_{n d} !} p_{1}^{b_{1}} p_{2}^{b_{2}} \ldots p_{d_{n}}^{b_{b_{n}}}$,

such that conditions (Eq. (1)) are satisfied.

Maximum Likelihood Estimates (MLE) of the probabilities $p_{d}$ from Eq. (2) can be obtained through the maximum likelihood function $L$ (Cox, 1984). For a sample of size $r$ it can be written as Eq. (3):

$\mathrm{L}=\prod_{\mathrm{j}=1}^{\mathrm{r}} \frac{\mathrm{b} !}{\mathrm{b}_{1, \mathrm{j}} ! \mathrm{b}_{2, \mathrm{j}} ! \ldots \ldots \ldots \mathrm{b}_{\mathrm{nd}, \mathrm{j}} !} \mathrm{p}_{1}^{\mathrm{b}_{1, \mathrm{j}}} \mathrm{p}_{2}^{\mathrm{b}_{2, \mathrm{j}}} \ldots \mathrm{p}_{\mathrm{d}_{\mathrm{n}}}^{\mathrm{b}_{\mathrm{n}, \mathrm{j}}}$,

while its natural logarithm is:

$$
\ln L=\sum_{j=1}^{r} \ln \left(b^{\prime}\right)-\sum_{j=1}^{r} \sum_{d=1}^{n d} \ln \left(b_{d, j}\right)+\sum_{d=1}^{n d}\left[\ln \left(p_{d}\right) \sum_{j=1}^{r} b_{d, j}\right]
$$

The maximum of the function from Eq. (4), given the constraint $p_{1}+p_{2}+\ldots+p_{n d}=1$, can be found from the system of equations obtained by partial derivation of the Langrange function $L$.

$\Lambda=\sum_{j=1}^{r} \ln \left(b^{b}\right)+\sum_{d=1}^{n d}\left[\ln \left(p_{d}\right) \sum_{j=1}^{r} b_{d, j}\right]-\sum_{j=1}^{r} \sum_{d=1}^{n d} \ln \left(b_{d, j}\right)+\gamma\left(1-p_{1}-p_{2}-\ldots \ldots . .-p_{d d}\right)$

where $\gamma$ is a Langrangian coefficient. Then the solution of the system of equations:

$\frac{\partial \Lambda}{\partial \mathrm{p}_{1}}=\frac{\sum_{\mathrm{j}=1}^{\mathrm{r}} \mathrm{b}_{1, \mathrm{j}}}{\mathrm{p}_{1}}-\gamma=0$
$\frac{\partial \Lambda}{\partial \mathrm{p}_{2}}=\frac{\sum_{\mathrm{j}=1}^{\mathrm{r}} \mathrm{b}_{2, \mathrm{j}}}{\mathrm{p}_{2}}-\gamma=0$

$\frac{\partial \Lambda}{\partial \mathrm{p}_{\mathrm{dn}}}=\frac{\sum_{\mathrm{j}=1}^{\mathrm{r}} \mathrm{b}_{\mathrm{dn}, \mathrm{j}}}{\mathrm{p}_{\mathrm{dn}}}-\gamma=0$

gives the MLE of the multinomial probabilities:

$\widehat{\mathrm{p}}_{\mathrm{d}}=\frac{\sum_{\mathrm{j}=1}^{\mathrm{r}} \mathrm{b}_{\mathrm{d}, \mathrm{j}}}{\sum_{\mathrm{j}=1}^{\mathrm{r}} \sum_{\mathrm{d}=1}^{\mathrm{nd}} \mathrm{b}_{\mathrm{d}, \mathrm{j}}}$ for $d=1,2, \ldots, n_{d}$.

Thus the MLE of probabilities of boarding at door $d$ depend on the total number of boarding passengers observed at a particular door and the overall total number of boarding passengers at all doors and for all trains in the sample. It does not depend on the number of boarding passengers per train $b$. 
The distribution of the alighting passengers per door can be described in a similar fashion as the distribution of the boarding passengers.
The MLE of probabilities $p_{d}\left(d=1,2, \ldots, n_{d}\right)$ computed from the Bloor Station data are given in Table 1.

\section{Table 1}

MLE of the Probabilities to Board and Alight at a Door, Bloor Station, Toronto

\begin{tabular}{|l|l|l|l|l|l|l|l|l|l|l|l|l|}
\hline Door & $\mathbf{1}$ & $\mathbf{2}$ & $\mathbf{3}$ & $\mathbf{4}$ & $\mathbf{5}$ & $\mathbf{6}$ & $\mathbf{7}$ & $\mathbf{8}$ & $\mathbf{9}$ & $\mathbf{1 0}$ & $\mathbf{1 1}$ & $\mathbf{1 2}$ \\
\hline Alighting & 0.030 & 0.046 & 0.053 & 0.065 & 0.061 & 0.053 & 0.069 & 0.065 & 0.064 & 0.052 & 0.042 & 0.038 \\
\hline Boarding & 0.088 & 0.132 & 0.116 & 0.101 & 0.085 & 0.053 & 0.046 & 0.037 & 0.036 & 0.027 & 0.030 & 0.026 \\
\hline Door & $\mathbf{1 3}$ & $\mathbf{1 4}$ & $\mathbf{1 5}$ & $\mathbf{1 6}$ & $\mathbf{1 7}$ & $\mathbf{1 8}$ & $\mathbf{1 9}$ & $\mathbf{2 0}$ & $\mathbf{2 1}$ & $\mathbf{2 2}$ & $\mathbf{2 3}$ & $\mathbf{2 4}$ \\
\hline Alighting & 0.039 & 0.038 & 0.033 & 0.039 & 0.045 & 0.046 & 0.037 & 0.029 & 0.027 & 0.015 & 0.007 & 0.005 \\
\hline Boarding & 0.029 & 0.021 & 0.014 & 0.020 & 0.018 & 0.023 & 0.018 & 0.013 & 0.014 & 0.017 & 0.018 & 0.015 \\
\hline
\end{tabular}

Unfortunately, the available survey data did not allow a rigorous statistical testing of the hypothesis of a multinomial passenger distribution among doors, due to insufficient sample size (Thomson, 1987) . Nevertheless, an attempt was made to obtain at least some additional intuitive information. Namely, it was noticed that there were 10 trains that had between 128 and 138 boarding passengers per train. This led to the idea of approximating their total number of passengers per train to $n=133$ (the middle value), and compare the model expected number of passengers at door $d, E\left[b_{d}\right]=n p_{d}$ and its variance $\operatorname{Var}\left[b_{d}\right]=n p_{d}\left(1=p_{d}\right)$, with the actual data. This was merely done to eventually detect any large discrepancies between the proposed model and the actual data.

The trains included in the test, the number of passengers per $\mathrm{TU}$, and the sample and model expected values and standard deviations are given in Table 2. The same data is shown graphically in Fig. 4.

From Table 2 and Fig. 4 it can be seen that despite the small sample and other irregularities in the comparison that stem from the averaged number of passengers per train, it seems that the multinomial passenger distribution hypothesis appears to be an appropriate model for describing the passenger distribution among TU doors.

\section{Discussion of the Results}

The available data did not allow rigorous statistical testing, and this is true especially for the distribution of alighting passengers where the number of trains with the similar total number of passengers per train did not make big enough statistical sample.

Nevertheless, the results of the analysis have shown that the multinomial passenger distribution hypothesis appears to be an appropriate model for describing the passenger distribution among TU doors. The statistical analysis for the boarding passengers has shown quite strong match of the model data with the one observed at Bloor metro station in Toronto.

Another important finding is the confirmation that the passenger distribution on station platform is influenced by the position of station entrances/exits. 
In the analyzed case, the boarding passengers were concentrated at the first car of the train, which is the closest to the station's only transfer and entrance point. The distribution of alighting passengers is somewhat more diffused, but still with a higher concentration of passengers at the doors of the first and second train car which are again the closest to the only transfer point. An interesting observation is the smaller peak of alighting passengers near the second smaller exit from the station platform.
These findings support the thesis that the passenger distribution among train doors is strongly influenced by the position of the platform exits/entrances. Moreover, it seems that this distribution is fairly constant at least over some period of time during the operation. The same general shape of the distribution of the alighting and boarding passengers, defined through the percent of passengers per door, was followed by the alighting and boarding passengers of all 44 surveyed trains, during the entire survey period.

Table 2

Distribution of Boarding Passengers among Doors: Test of the Multinomial Distribution Model Toronto, Bloor Station 4:36 - 6:36 pm (Sample of Trains with 128 to 138 Passengers per Train)

\begin{tabular}{|c|c|c|c|c|c|c|c|c|c|c|c|c|}
\hline Doors & 1 & 2 & 3 & 4 & 5 & 6 & 7 & 8 & 9 & 10 & 11 & 12 \\
\hline Train 7 & 20 & 16 & 18 & 14 & 9 & 4 & 5 & 9 & 3 & 3 & 5 & 5 \\
\hline Train 8 & 8 & 16 & 24 & 12 & 15 & 4 & 4 & 5 & 1 & 5 & 5 & 3 \\
\hline Train 11 & 12 & 23 & 19 & 17 & 12 & 8 & 7 & 5 & 3 & 2 & 3 & 4 \\
\hline Train 12 & 12 & 19 & 20 & 12 & 19 & 6 & 7 & 3 & 7 & 3 & 4 & 1 \\
\hline Train 13 & 21 & 18 & 13 & 10 & 11 & 6 & 6 & 6 & 4 & 2 & 3 & 3 \\
\hline Train 14 & 15 & 22 & 20 & 17 & 13 & 6 & 4 & 6 & 0 & 3 & 2 & 2 \\
\hline Train 25 & 14 & 25 & 18 & 13 & 11 & 12 & 6 & 7 & 3 & 1 & 3 & 1 \\
\hline Train 32 & 11 & 9 & 11 & 9 & 10 & 9 & 8 & 4 & 6 & 5 & 7 & 0 \\
\hline Train 40 & 7 & 29 & 15 & 17 & 15 & 6 & 9 & 8 & 4 & 1 & 4 & 0 \\
\hline Train 42 & 14 & 16 & 17 & 11 & 3 & 5 & 12 & 7 & 6 & 2 & 0 & 3 \\
\hline $\mathbf{p}$ & 0.09 & 0.13 & 0.12 & 0.10 & 0.08 & 0.05 & 0.05 & 0.04 & 0.04 & 0.03 & 0.03 & 0.03 \\
\hline Sample mean & 13.40 & 19.30 & 17.50 & 13.20 & 11.80 & 6.60 & 6.80 & 6.00 & 3.70 & 2.70 & 3.60 & 2.20 \\
\hline Model mean & 11.74 & 17.54 & 15.43 & 13.48 & 11.28 & 7.05 & 6.08 & 4.99 & 4.78 & 3.57 & 4.01 & 3.41 \\
\hline Sample SD & 4.53 & 5.66 & 3.75 & 2.97 & 4.26 & 2.46 & 2.44 & 1.83 & 2.21 & 1.42 & 1.90 & 1.69 \\
\hline Model SD & 3.27 & 3.90 & 3.69 & 3.48 & 3.21 & 2.58 & 2.41 & 2.19 & 2.15 & 1.86 & 1.97 & 1.82 \\
\hline Doors & 13 & 14 & 15 & 16 & 17 & 18 & 19 & 20 & 21 & 22 & 23 & 24 \\
\hline Train 7 & 3 & 1 & 2 & 1 & 2 & 3 & 3 & 0 & 2 & 2 & 1 & 1 \\
\hline Train 8 & 4 & 3 & 2 & 1 & 1 & 7 & 2 & 2 & 1 & 1 & 4 & 0 \\
\hline Train 11 & 5 & 1 & 2 & 2 & 0 & 2 & 1 & 0 & 0 & 1 & 3 & 2 \\
\hline Train 12 & 2 & 5 & 0 & 2 & 3 & 1 & 3 & 1 & 0 & 2 & 3 & 0 \\
\hline Train 13 & 6 & 2 & 4 & 0 & 3 & 8 & 3 & 1 & 2 & 1 & 2 & 1 \\
\hline Train 14 & 4 & 5 & 3 & 2 & 3 & 3 & 1 & 1 & 2 & 3 & 0 & 1 \\
\hline Train 25 & 2 & 4 & 0 & 1 & 2 & 3 & 2 & 2 & 1 & 1 & 1 & 0 \\
\hline Train 32 & 4 & 1 & 0 & 3 & 4 & 8 & 1 & 3 & 4 & 3 & 4 & 4 \\
\hline Train 40 & 2 & 1 & 2 & 1 & 3 & 1 & 4 & 1 & 1 & 0 & 1 & 3 \\
\hline Train 42 & 3 & 4 & 3 & 2 & 5 & 0 & 5 & 0 & 1 & 4 & 3 & 2 \\
\hline $\mathbf{p}$ & 0.03 & 0.02 & 0.01 & 0.02 & 0.02 & 0.02 & 0.02 & 0.01 & 0.01 & 0.02 & 0.02 & 0.01 \\
\hline Sample mean & 3.50 & 2.70 & 1.80 & 1.50 & 2.60 & 3.60 & 2.50 & 1.10 & 1.40 & 1.80 & 2.20 & 1.40 \\
\hline Model mean & 3.92 & 2.88 & 1.95 & 2.72 & 2.39 & 3.13 & 2.39 & 1.74 & 1.81 & 2.27 & 2.44 & 1.97 \\
\hline Sample SD & 1.35 & 1.70 & 1.40 & 0.85 & 1.43 & 2.99 & 1.35 & 0.99 & 1.17 & 1.23 & 1.40 & 1.35 \\
\hline Model SD & 1.95 & 1.68 & 1.39 & 1.63 & 1.53 & 1.75 & 1.53 & 1.31 & 1.34 & 1.50 & 1.55 & 1.39 \\
\hline
\end{tabular}

$P$ - MLE of probabilities to board at a door

$S D$ - standard deviation 


\section{Conclusion}

Any analysis of the metro line performance characteristics (sustainable capacity and level of service) requires more deeper insight into behavior of passengers on metro station platform since it directly influences the station dwell time and the minimum sustainable headway between trains. The number of research done on this subject has been quite limited so far.

The rather comprehensive survey data at Bloor station in Toronto and the analysis described in this article has allowed a conclusion that the multinomial passenger distribution might be a good model for description of the passenger distribution among train doors.

In addition, the analysis has shown the influence of the position of station entrances/exits on the passenger distribution on the station platform and in the trains.

An important finding is that this distribution appears to be stable over the time.

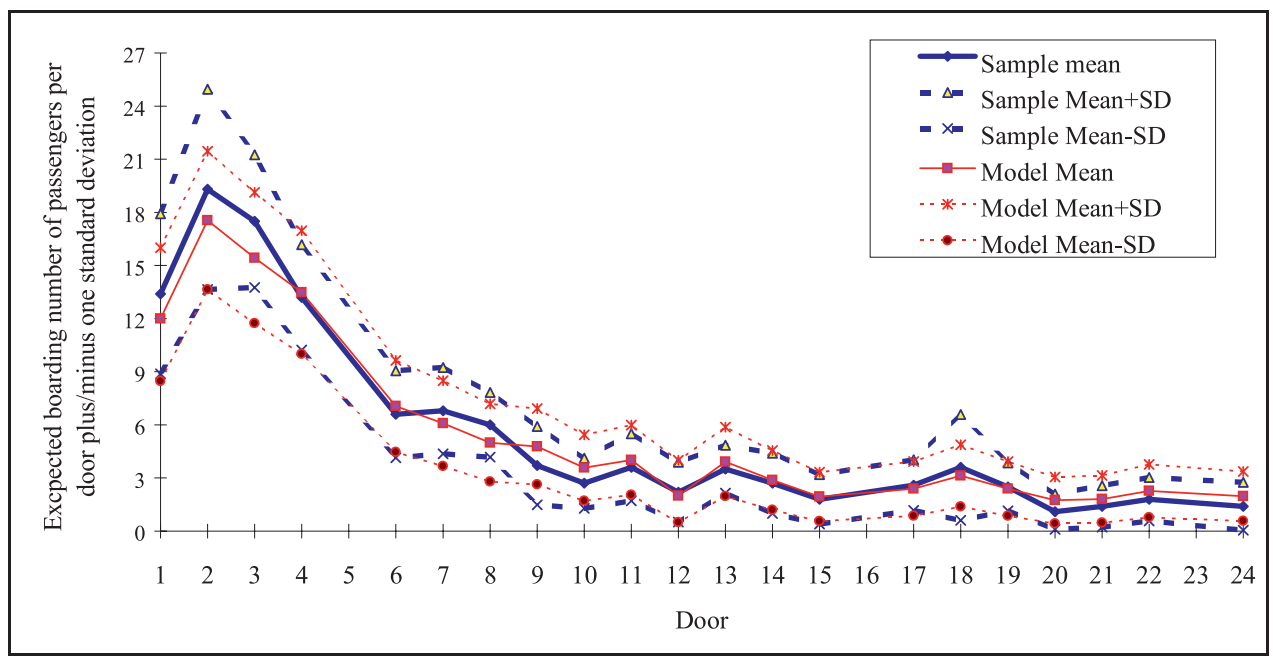

Fig. 4.

Comparison of the Model and Actual Data of the Number of Boarding Passengers per Door

\section{Acknowledgements}

The data used in this research were made available to me courtesy of Prof. Gerald N. Stuart from University of Toronto and were collected as part of the study done by Bruce
Mori at the same University (Mori, 1988). The author of this paper would like to express special thanks to Prof. Gerald N. Stuart from University of Toronto, for the great help by making to me available the data from video recordings on Bloor station in Toronto. 


\section{References}

Cox, C. 1984. An Elementary Introduction to Maximum Likelihood Estimation for Multinomial Models: Birch's Theorem and the Delta Method, The American Statistician. DOI: http://dx.doi.org/10.1080/00031305.1984.1048 3226, 38(4): 283-287.

Krstanoski, N. 1996. Rapid Transit Line Performance Analysis: A Stochastic Approach. A Dissertation in Systems Engineering, University of Pennsylvania, USA.

Mori, B. 1988. A Study of the Dwell Time at Urban Rail Transit Stations. Master Thesis. Department of Civil Engineering, University of Toronto.

Szplett, D.; Wirasinghe, S.C. 1984a. An Investigation of Passenger Interchange and Train Standing Time at LRT Stations: (i) Alighting, Boarding and Platform Distribution of Passengers, Journal of Advanced Transportation. DOI: http://dx.doi.org/10.1002/ atr.5670180102, 18(1): 1-12.

Szplett, D.; Wirasinghe, S.C. 1984b. An Investigation of Passenger Interchange and Train Standing Time at LRT Stations: (ii) Estimation of standing Time, Journal of Advanced Transportation. DOI: http://dx.doi.org/10.1002/ atr.5670180103, 18(1): 13-24.

Thomson, S.K. 1987. Sample Size for Estimating Multinomial Proportions, The American Statistician. DOI: http://dx.doi.org/10.1080/00031305.1987.104 75440, 41(1): 42-46.

Wu, Y.; Rong, J.; Wei, Z.; Liu, X. 2012. Modeling Passenger Distribution on Subway Station Platform prior to the Arrival of Trains, Transportation Research Board Annual Meeting 2012, Paper \#12.15 p. 